\title{
OPTIMAL INCOME TRANSFER PROGRAMS: INTENSIVE VERSUS EXTENSIVE LABOR SUPPLY RESPONSES*
}

\author{
EMmanuel SAEZ
}

This paper analyzes optimal income transfers for low incomes. Labor supply responses are modeled along the intensive margin (intensity of work on the job) and along the extensive margin (participation into the labor force). When behavioral responses are concentrated along the intensive margin, the optimal transfer program is a classical Negative Income Tax program with a substantial guaranteed income support and a large phasing-out tax rate. However, when behavioral responses are concentrated along the extensive margin, the optimal transfer program is similar to the Earned Income Tax Credit with negative marginal tax rates at low income levels and a small guaranteed income. Carefully calibrated numerical simulations are provided.

\section{INTRODUCTION}

During the twentieth century, most developed countries have adopted large government-managed income support programs. These programs have generated substantial controversy. While it is generally recognized that they considerably improve the wellbeing of the disadvantaged, some have pointed out that they may substantially reduce the incentives to work, and thus have large efficiency costs that may outweigh the redistributive gains. As the efficiency costs arise from the labor supply responses to the transfer or tax programs, it is obviously crucial to examine and model these behavioral responses as accurately as possible. The empirical literature on labor supply has emphasized two margins of labor supply responses (see Heckman [1993]). First, individuals can respond along the intensive margin by varying their hours or intensity of work on the job. Second, individuals may respond along the extensive margin. That is, they can decide whether or not to enter the labor force. The empirical literature has shown that extensive labor supply elasticities are significant for low income earners. For example, Eissa and Liebman [1996] and Meyer and Rosenbaum [2001] show that the development of the Earned Income Tax Credit in the United States has had strong positive effects on labor force participation of beneficiaries. By

* I thank Timothy Besley, David Cutler, Peter Diamond, Esther Duflo, Edward Glaeser, Jonathan Gruber, James Heckman, Lawrence Katz, Michael Kremer, John McHale, Bruce Meyer, Thomas Piketty, David Spector, numerous seminar participants, and anonymous referees for helpful comments and discussions.

๑ 2002 by the President and Fellows of Harvard College and the Massachusetts Institute of Technology.

The Quarterly Journal of Economics, August 2002 
a. Negative Income Tax (NIT)

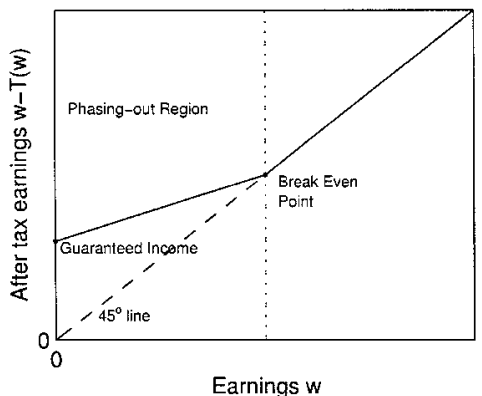

b. Earned Income Tax Credit (EITC)

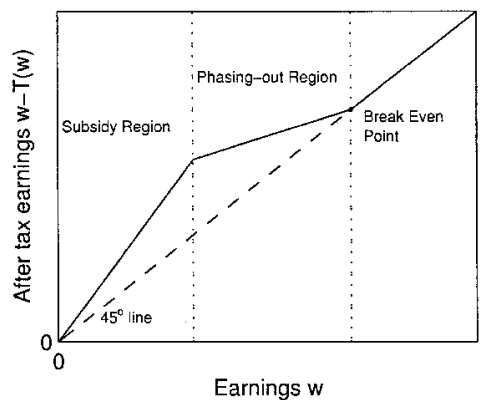

FIGURE I

contrast, the evidence of responses along the intensive margin seems much more limited. Most estimates of hours of work elasticities conditional on working are small (see Pencavel [1986] and Blundell and MaCurdy [1999] for surveys). The aim of this paper is to show that the margin of the behavioral response is a key element to take into consideration when designing an optimal transfer scheme.

The optimal income tax literature has developed models to analyze the design of transfer programs but has focused, following the seminal contribution of Mirrlees [1971], almost exclusively on the intensive margin of response. Mirrlees [1971] showed that, in that context, the optimal tax marginal tax rates at any income level cannot be negative. Moreover, numerical simulations have shown that, in this model, optimal rates at the bottom are very high (see, e.g., Tuomala [1990] and Saez [2001]). Redistribution thus takes the form of a guaranteed income level that is taxed away at substantial rates as depicted in Figure Ia. Such a transfer scheme is known as a Negative Income Tax (NIT) program: it provides the largest transfers to the lowest income earners who are presumably the most in need of support. In accordance with the theory, many European countries use NITtype programs to redistribute toward zero or low income earners. In the United States there is no universal income support program. However, most categorical transfer programs such as Temporary Assistance for Needy Families (TANF) for single mothers, Food Stamps, Disability Insurance, and Supplemental Social Security Income for the old are also designed as NIT programs. 
However, NIT-type programs also have adverse effects on labor supply along the extensive margin and have often been held responsible for the low working rates among welfare recipients in the United States (see, e.g., Murray [1984]). This has led politicians to advocate programs that would make work sufficiently attractive to reduce the need for income support. In the early 1990s the Earned Income Tax Credit (EITC) program was substantially increased and is now the largest cash transfer program for the poor in the United States. The EITC program, as depicted on Figure Ib, is fundamentally different from an NIT program: it does not provide any income support for individuals with no earnings, but all earnings below a given threshold are partially matched by the government. In economic terms, this is equivalent to negative marginal tax rates at the bottom of the income distribution. Obviously, relative to an NIT program, incentives to enter the labor force are enhanced with an EITC program. The cost is that no support is provided to the neediest people with no earnings. Moreover, as shown in Figure Ib, the earned income tax credit has also to be taxed away at some point farther up the income distribution and thus imposes labor supply disincentives along the intensive margin for workers in the phasing-out region.

As mentioned above, optimal marginal tax rates cannot be negative in the Mirrlees [1971] model, ruling out EITC-type of transfers at the optimum. However, Diamond [1980] has developed a simple optimal tax model, where hours and wages are fixed but people can choose whether or not to participate in the labor force. In that model, the Mirrlees [1971] result breaks down, and optimal marginal tax rates may be negative for some income ranges. Diamond's study is theoretical, and no attempt is made to express optimal tax formulas in terms of elasticities or to assess the importance of the participation decision margin relative to the standard intensive margin of response. As a result, that study has not been followed up on to cast light on the EITC versus NIT debate. $^{1}$

The goal of this paper is to cast light on the NIT versus EITC controversy using the methods of optimal income taxation. This

1. Note also that the retirement decision, or the decision to migrate to other jurisdictions, is a binary choice akin to a labor force participation decision. As a result, models of optimal social security taxes and benefits, such as Diamond and Mirrlees [1978] or Diamond, Helms, and Mirrlees [1980], or models of optimal income taxation with migration such as Mirrlees [1982] are related to what is done in the present paper. 
paper develops a unifying framework encompassing labor supply responses both along the intensive and extensive margin. It shows that an NIT program with a substantial guaranteed income level and high phasing-out rates is optimal when labor supply responses are concentrated along the intensive margin. However, when labor supply responses are concentrated along the extensive margin, then the optimal transfer is similar to an EITC with negative marginal tax rates at the bottom and a smaller guaranteed income for nonworkers. In the paper, optimal tax rates formulas are derived as a function of the behavioral elasticities estimated by the empirical literature. Therefore, using the estimates of both intensive and extensive behavioral elasticities from empirical studies, it is possible to assess the optimal shape and the optimal size of the transfer program. This paper provides a number of numerical simulations to investigate this point further. For realistic elasticities, the optimal program provides a moderate guaranteed income, but imposes a zero marginal tax rate at the bottom and taxes away at substantial rates the guaranteed income farther up the earnings distribution.

The paper is organized as follows. Section II presents the models of intensive and extensive responses. It derives optimal tax formulas in each of these two polar cases, and in the case where the two margins of response are present. Section III discusses the empirical literature on income maintenance programs and presents numerical simulations of optimal transfer schemes. Section IV concludes and discusses avenues for future research.

\section{Extensive versus Intensive Response Models}

The goal of this section is to develop a model of labor supply and optimal taxation to understand how the nature of labor supply responses-intensive versus extensive-affects the shape of the optimal tax and transfer schedule. Therefore, I introduce first the pure extensive model or participation model and then the pure intensive model or effort model, and consider afterwards a mix of the two polar models. Because I want to focus on the intensive versus extensive labor supply response issue, I make two important simplification assumptions.

First, I consider income taxation only at the individual level and thus completely ignore the secondary earner labor choice decision issue that arises in the context of household income taxation. The joint taxation problem is obviously important but 
considerably complicates the analysis and thus is better left for future research.

Second, I assume that the government bases redistribution on realized earnings only. That is, the government does not condition transfers and taxes on other observable information. As discussed in the Introduction, this is consistent with the experience of European countries such as France but at odds with the U. S. transfer system. As pointed out by Akerlof [1978], in theory, the government should base redistribution not only on income but also on observable characteristics such as age, family status, etc. that are correlated with skills and ability to work. However, within categories of people with the same characteristics, such as single-parent families, the government continues to face a classic optimal income tax problem where the model developed here should be relevant. ${ }^{2}$

Two other features of the present model are worth noting.

First, the extensive elasticity is not an intrinsic parameter but depends on the institutional features of the labor market. For example, if employers allow greater flexibility in hours of work for employees, it might become easier for individuals to adjust labor supply along the intensive margin. As a result, the extensive elasticity would decrease and the intensive elasticity increase. Similarly, the relative size of extensive versus intensive elasticities depends on the time period upon which the income tax is assessed. If the time period is a lifetime, then, as almost every person does some work over his lifetime, the extensive margin becomes irrelevant, and the behavioral responses are necessarily intensive. On the other hand, if the time period is very short, such as a day or an hour, the extensive margin becomes prominent. In the United States, individual income taxation and the EITC are computed on an annual basis, but most welfare programs such as TANF and Food Stamps are on a monthly basis. In the model, I eliminate this complication by considering the time period as fixed, and for numerical simulations I will consider elasticities based on annual earnings as is usually done in empirical studies. Therefore, in the model, it is constructive to think that both taxes

2. When the characteristics are immutable such as age, the government solves standard optimal tax problems independently for each category (see Kremer [1997]). However, when characteristics are not immutable or are observed with error such as family or disability status, the problem is greatly complicated, and it is not clear to what extent the government should condition transfers on these noisy characteristics. This issue was first raised by Akerlof [1978] and deserves more investigation. 
and transfers are based on annual earnings. I come back to this timing issue in the conclusion.

Second, I adopt a traditional approach where the government maximizes a classical welfare function depending on individual utilities. Two recent important studies by Besley and Coate $[1992,1994]$ have investigated the design of income maintenance programs when the objective of the government is not to maximize social welfare but to alleviate poverty. They show that in this context, work requirements (workfare) might be an effective screening device to target welfare to the less skilled individuals. In the present standard welfarist model, this issue does not arise.

\section{II.1. The General Framework}

To simplify the exposition, I consider a discrete model of occupational choice. It is possible to develop a continuous model that is equivalent. ${ }^{3}$ Thus, in the model, there are $I+1$ types of occupations: the unemployed earning $w_{0}=0$, and $I$ types of jobs paying salaries $w_{i}$ for $i=1, \ldots, I$. The salaries $w_{i}$ are increasing in $i, 0<w_{1}<\ldots<w_{I}$, and correspond to occupations with increasing skills. As is standard in the optimal income tax literature, I assume that there is perfect substitution of labor types in the production function and thus that the salaries $w_{i}$ are fixed. As discussed above, a key assumption of the paper is that the government is only able to observe income levels and thus can condition taxation only on income. The net taxes paid by each class of individuals are denoted by $T_{i}$. This tax scheme embodies both taxes and transfers. Therefore, in contrast to the actual situation where the income tax is administered separately from the welfare programs, the income tax and transfer program are fully integrated in the present model. ${ }^{4}$ For example, if $T_{i}<0$, then workers in occupation $i$ receive a net transfer from the government. The after-tax income in occupation $i$ is denoted by $c_{i}=$ $w_{i}-T_{i}$.

The total population is normalized to one, and I denote by $h_{i}$ the proportion of individuals in occupation $i$ (so that $h_{0}+h_{1}+$ $\ldots+h_{I}=1$ ). Individuals have heterogeneou s tastes and choose their occupation $i$ according to the relative after-tax rewards in

3. Such a continuous model is developed in an earlier version of the paper [Saez 2000].

4. As labor supply decisions depend on the final budget constraint incorporating all taxes and transfers, there is no need to distinguish taxes from transfers in optimal tax models. 
each occupation. For example, if the rewards for work are reduced relative to welfare benefits $c_{0}$, then presumably some individuals will drop out of the labor force. Thus, in the aggregate, the fraction of individuals choosing occupation $i$ depends on after-tax rewards in all occupations: $h_{i}=h_{i}\left(c_{0}, c_{1}, \ldots, c_{I}\right)$. The magnitude of labor supply responses is embodied in the functions $h_{i}$. High taxation and redistribution levels, for example, may shift labor supply away from highly productive activities toward lower productive jobs or unemployment. As these aggregated functions $h_{i}$ are a sufficient statistic for labor supply responses in the optimal tax analysis, the description of the formal underlying structure of individual utilities is not essential for the analysis and is therefore only presented in the Appendix.

The government set taxes $T_{i}$ so as to maximize welfare which is a weighted sum of individual utilities (see the Appendix). Taxes must finance transfers and government consumption. I assume that government consumption per capita is fixed and equal to $H$. The government budget constraint is

$$
\sum_{i=0}^{I} h_{i} T_{i}=H .
$$

The welfare function can be simply characterized by marginal social welfare weights (expressed in terms of the value of public funds) that the government sets for each of the $I+1$ of occupations. These weights are denoted by $g_{i}, i=0,1, \ldots, I$ and represent the value (in terms of public funds) of giving an additional dollar to an individual in occupation $i$. Put another way, the government is indifferent between giving one more dollar to an individual in occupation $i$ and $g_{i}$ more dollars of public funds. As we will see, these weights are a sufficient statistic for the redistributive tastes of the government in the optimal transfer formulas that we derive. The formal definition of these weights is given in the Appendix. If the government values redistribution, then the lower the earnings level of the individual, the higher the social marginal value of an extra dollar for that individual. As a result, the weights $g_{i}$ are decreasing in $i$.

The marginal weight $g_{0}$ deserves special attention. The pool of unemployed individuals is presumably very heterogeneous. Some individuals are unemployed because they cannot work because of disabilities or very low skill levels. Other unemployed individuals may be able to work but choose not to because they 
may have low tastes for work. Whether the unemployed really cannot work or are lazy is of critical importance to assess whether they deserve to get transfers. Liberals tend to hold the former view, and conservatives the latter. A conservative government willing to redistribute toward the "deserving poor" but not toward the "lazy poor" might thus set a lower weight for the unemployed than for the low skilled workers $\left(g_{0}<g_{1}\right)$. On the other hand, a liberal government might consider that the unemployed are in more need than the low skilled workers and thus set $g_{0}>g_{1} \cdot{ }^{5}$ Of course, whether the unemployed can work or not is not uniquely an ideological controversy, and is also an empirical issue that might be tackled analytically. ${ }^{6}$ Here, we take as given the redistributive tastes and views of the government, but we analyze in detail how the pattern of social weights affects the optimal tax and transfer schedule.

Finally, it is important to note that the social weights $g_{i}$ are not exogenous parameters but depend on the tax schedule $\left(c_{0}, \ldots, c_{I}\right)$ that is currently implemented (see the Appendix for a formal discussion of this point). For example, if after-tax incomes are equalized across occupations, then there is no reason to desire further redistribution at the margin, and the marginal weights should no longer be decreasing with $i$.

For the numerical simulations I posit that the social weights $g_{i}$ are a simple decreasing function of disposable income: $g_{i}=$ $g\left(c_{i}\right) / p$, where $p$ is the marginal value of public funds. In this case, the function $g(\cdot)$ is taken as exogenous and reflects the absolute redistributive tastes of the government. The function $g(\cdot)$ summarizes in a transparent way the redistributive tastes of the government and is decreasing when the government values redistribution. It is important to note, as described in the Appendix, that this method is fully consistent with the classical welfare approach which maximizes a weighted sum of individual utilities. The individual weights of the classical approach can always be chosen such that the resulting $g_{i}$ 's match the desired marginal social welfare function $g(\cdot)$.

5. It can also be argued that conservatives do not set low intrinsic weights on the unemployed but believe that the disincentive effect of giving to the unemployed is higher than giving to the working poor. Economic theory shows us that it is critical to make a clear conceptual distinction between tastes for redistribution and behavioral elasticities.

6. Bound [1989, 1991] and Parsons [1991] present a lively scientific debate on which fraction of disability insurance recipients in the United States can or cannot work. 
The approach using the function $g(\cdot)$ directly is a useful shortcut because it does not require explicitly specifying individual utilities and is therefore simpler to implement numerically. It also summarizes in a much more transparent way the redistributive tastes of the government than the classical individual weights and simplifies the issue of making interpersonal utility comparisons when tastes are very heterogeneous.

I consider as an important special benchmark case the situation with no income effects. In this case, increasing all after-tax levels $c_{i}$ by a constant amount $R$ does not change the individual occupational choice decisions and thus does not affect the aggregate occupational distribution $h_{i}$. Formally, $h_{i}\left(c_{0}+R, c_{1}+\right.$ $\left.R, \ldots, c_{I}+R\right)=h_{i}\left(c_{0}, c_{1}, \ldots, c_{I}\right)$ for all $i$ and $R$. With no income effects, a marginal dollar of public funds is valued as much as an additional dollar redistributed to all classes, and therefore (see the Appendix for a formal proof),

$$
\sum_{i=0}^{I} h_{i} g_{i}=1 .
$$

Equation (2) provides a normalization of the welfare weights $g_{i}$.

The model where each $h_{i}$ depends on all after-tax rewards $\left(c_{0}, \ldots, c_{I}\right)$ is of course too general to provide interesting results. Therefore, we specialize this model to two polar cases of interest: the extensive response model and the intensive response model.

\section{II.2. Extensive Responses}

In this first model, individuals respond only through the extensive margin: the labor supply decision is binary-either work or not work. The empirical literature has shown that this margin of response is important especially at the low income end. This can be due to fixed costs of work or because employers require employees to work a minimum number of hours per week. This can be modeled in the framework described above as follows. Each individual has a skill level $i \in\{0,1, \ldots, I\}$ and may only choose either to work in occupation $i$ corresponding to his skill or to be unemployed. ${ }^{7}$ Therefore, the only decision is a participation decision. The decision to participate depends on the relative after- 
tax incomes when working $c_{i}$ and when unemployed $c_{0}$. This model is obviously a crude simplification of reality but captures the extensive margin labor supply decision. As I first assume away income effects, the decision to participate depends only on the difference $c_{i}-c_{0}$. Presumably, if disposable income is higher when unemployed than when working, nobody would choose to work. Therefore, I assume that $h_{i}\left(c_{i}-c_{0}\right)=0$ when $c_{i} \leq c_{0}$. As a result, it is never optimal for the government to set $c_{i}<c_{0}$, and thus I assume that $c_{i} \geq c_{0}$ for all $i$.

The size of the behavioral responses is captured by the elasticity of participation with respect to the difference in after-tax incomes. Formally, I define for $i=1, \ldots, I$,

$$
\eta_{i}=\frac{c_{i}-c_{0}}{h_{i}} \frac{\partial h_{i}}{\partial\left(c_{i}-c_{0}\right)} .
$$

This elasticity measures the percentage number of employed workers in occupation $i$ who decide to leave the labor force when the difference between disposable incomes in employment and unemployment decreases by 1 percent. The framework underlying this elasticity, presented in the Appendix, is a heterogeneous population of workers (at each skill level) who are attached to the labor force in varying degrees according to their tastes for work. Let us now characterize the optimal tax and transfer schedule in this model.

Proposition 1. At the optimum, the optimal schedule is such that

$$
\frac{T_{i}-T_{0}}{c_{i}-c_{0}}=\frac{1}{\eta_{i}}\left(1-g_{i}\right) \text {. }
$$

Equations (4) for $i=1,2, \ldots, I$ and (1) define the optimal set of taxes $T_{i}$ for $i=0,1, \ldots, I$.

Proof. The formal proof of this proposition is presented in the Appendix. However, here I give a simple heuristic proof that illuminates the economics behind formula (4). In order to derive the optimal set of taxes $T_{i}$, I consider a small change $d T_{i}$ of $\operatorname{tax} T_{i}$ on occupation $i$. This tax change has two effects on tax revenue and welfare.

First, there is a mechanical increase in tax revenue equal to $h_{i} d T_{i}$ because workers with skill $i$ pay $d T_{i}$ additional taxes. By definition of the welfare weight $g_{i}$, this increase in tax revenue, however, is valued only $\left(1-g_{i}\right) h_{i} d T_{i}$ by the government because 
each dollar raised decreases the after-tax incomes of individuals in class $i$ and this income loss is valued $g_{i}$ by the government.

Second, there is a loss in tax revenue due to the behavioral response. The small tax changes induce $d h_{i}$ workers to leave the labor force. By definition of $\eta_{i}$ in (3), we have $d h_{i}=-h_{i} \eta_{i} d T_{i} /$ $\left(c_{i}-c_{0}\right)$. Each worker leaving the labor force induces a loss in tax revenue equal to $T_{i}-T_{0}$; therefore, the total behavioral cost is equal to $-\left(T_{i}-T_{0}\right) h_{i} \eta_{i} d T_{i} /\left(c_{i}-c_{0}\right)$. There is no change in welfare due to the behavioral response because workers leaving the labor force on the margin are indifferent between becoming unemployed and remaining employed. ${ }^{8}$

At the optimum, the sum of the mechanical and behavioral effects must be zero. Rearranging this equation immediately gives equation (4). It is important to note that, even though the weights $g_{i}$ vary with the tax schedule, the optimal tax formula depends only on the level of the $g_{i}$ 's.

QED

Let us assume that the government has redistributive tastes, so that $g_{0}>g_{1}>\ldots>g_{I}$. With no income effects, from (2) we know that the average (using population weights) value of the $g_{i}$ 's is one. Therefore, there is some $i^{*}$ such that $g_{i} \geq 1$ for $i \leq i^{*}$ and $g_{i}<1$ for $i>i^{*}$. The government wants to redistribute from high skilled occupations $i>i^{*}$ toward low skilled occupations $i \leq i^{*}$.

As depicted on Figure IIa, equation (4) then implies that $T_{i}-$ $T_{0}>0$ for $i>i^{*}$ and that $T_{i}-T_{0} \leq 0$ for $i \leq i^{*}$. When $i^{*}>0$, the government provides a higher transfer to low skilled workers (for whom $1 \leq i \leq i^{*}$ ) than to the unemployed even though the social marginal utility of consumption is highest for the unemployed. Therefore, when the government wants to redistribute toward the low income workers $\left(g_{i}>1\right.$ for low $\left.i\right)$, it provides them with a tax transfer $-T_{i}$ larger than the tax transfer to the unemployed $-T_{0}$. In other words, in this case the government implements a combined lump sum guaranteed income $-T_{0}$ and a negative marginal tax rate at the bottom (similar to the Earned Income Tax Credit) in order to increase the size of transfers as income increases. The cost of these two welfare programs is then fully financed by higher income earners.

The intuition for having higher transfer levels to the working poor than to the unemployed is depicted in Figure IIb. Starting

8. Note that this property cannot be used when the objective of the government is nonwelfarist. This is why welfare maximization objectives are in general easier to handle than nonwelfarist objectives. 

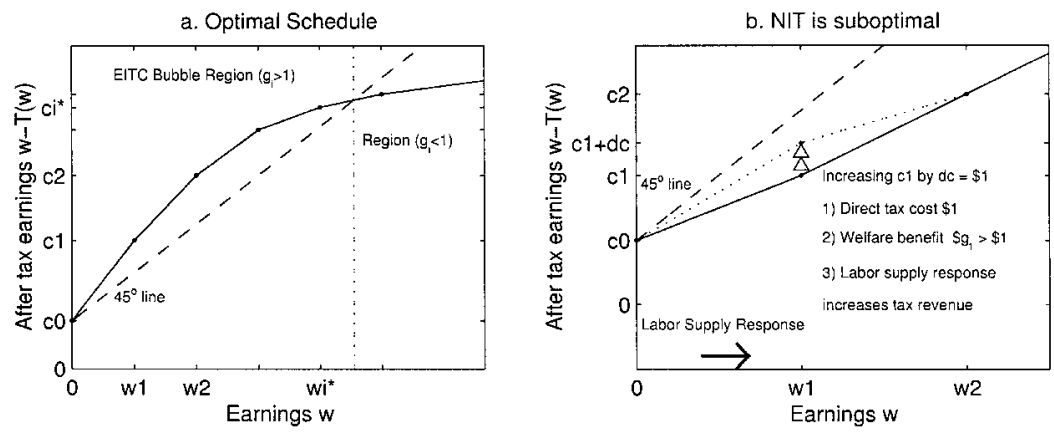

FIGURE II

from a situation with lower transfers to the working poor earning $w_{1}$ than to the unemployed, increasing the transfer to the working poor by one dollar costs one dollar in lost tax revenue but provides a welfare benefit valued $g_{1}$ dollars. This benefit is higher than one when $g_{1}>1$; that is, when the government values an extra dollar distributed to the working poor more than an extra dollar distributed uniformly over all individuals. This extra transfer to the working poor also encourages some of the unemployed to join the labor force which, in an NIT situation, increases tax revenue. As a result, it is unambiguously good to increase at the margin the transfer to low income workers implying that the initial situation depicted in Figure IIb is suboptimal. Note that if, as discussed above, the government does not value redistribution to the unemployed as much as to the working poor $\left(g_{0}<g_{1}\right)$, the EITC result is reinforced because a lower $g_{0}$ implies relatively higher weights for all the other groups including the working poor.

Finally, in two important cases, the EITC bubble disappears . First, when the government cares mostly about the welfare of the worse-off individuals (the extreme case being the Rawlsian objective), it might be the case that all weights (except $g_{0}$ ) are below one. In this case, $i^{*}=0$, and $T_{i} \leq T_{0}$ for all $i$, implying that the negative marginal tax rate component of the welfare program disappears and the transfer program is a classic negative income tax. Second, when the government has no redistributive tastes, then there is no guaranteed income, and the weights $g_{i}$ are 
constant and set so as to raise $H$ dollars per capita. ${ }^{9}$ In this case as well, tax liability is necessarily increasing with income.

In the case with income effects, labor supply depends not only on $c_{i}-c_{0}$ but also on $c_{0}$. In that situation, the average welfare weights may no longer be equal to one, and equation (2) needs to be modified (see Saez [2000]). However, the previous derivations carry over, and equation (4) remains valid. As a result, the EITC bubble result also carries through as long as the low skilled workers social marginal weights $g_{i}$ are above one.

\section{II.3. Intensive Responses}

The theory of optimal income taxation, following Mirrlees' [1971] seminal contribution, has mostly focused on the intensive labor supply response to taxes. Mirrlees' [1971] model is the classical static labor supply model where individuals choose their labor supply until marginal disutility of work equals marginal utility of money derived from the extra amount of work. Key to the analysis are the elasticities of labor supply with respect to tax rates. Piketty [1997] has developed the discrete version of the Mirrlees [1971] model. He considered only the Rawlsian case, but it is straightforward to adapt the model to any welfare weights. Here we follow his approach.

In the discrete type model, intensive responses can be modeled as follows. If the rewards of occupation $i$ are reduced relative to the lower income occupation $i-1$, then some individuals in occupation $i$ reduce their effort and switch to occupation $i-1$. I also assume here that there are no income effects implying that giving a uniform lump sum to all individuals does not affect the supply for each job. ${ }^{10}$ In this case and as shown formally in the Appendix, the functions $h_{i}$ can be written as $h_{i}\left(c_{i+1}-c_{i}, c_{i}-\right.$ $\left.c_{i-1}\right)$. When $c_{i+1}-c_{i}$ increases by $d c$ and when all the other differences $c_{j+1}-c_{j}$ for $j \neq i$ are kept constant, there is a displacement of workers from job $i$ to job $i+1$. The behavioral elasticities can be defined as

9. In the case where everybody can afford to pay $H$ in taxes, the government just sets a uniform lump sum tax equal to $H$ and all the $g_{i}$ 's are equal to one. However, in the realistic case where zero and low income earners cannot pay $H$, the government cannot implement the first best lump sum tax, and the weights $g_{i}$ are constant and strictly below one.

10. Income effects can be included in the analysis as in Saez [2001], but this substantially complicates the analysis. Moreover, as income effects along the intensive margin of response have, in general, been found to be small in the empirical literature, we consider only the simpler case with no income effects. 
a. Deriving the Optimal Tax

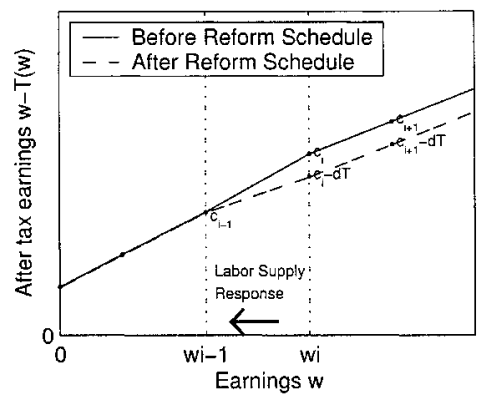

b. Negative Marginal Tax Rate is suboptimal

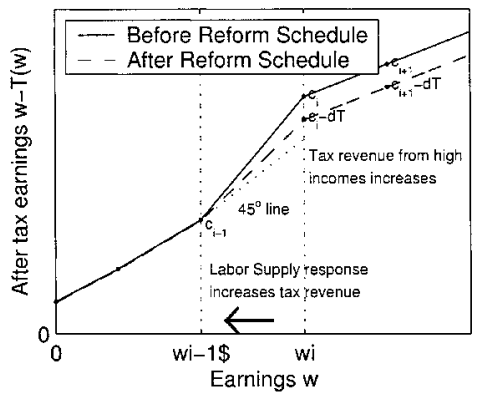

FIGURE III

$$
\zeta_{i}=\frac{c_{i}-c_{i-1}}{h_{i}} \frac{\partial h_{i}}{\partial\left(c_{i}-c_{i-1}\right)} .
$$

This elasticity measures the percentage increase in supply of job $i$ when $c_{i}-c_{i-1}$ is increased by 1 percent. I specify in the Appendix a set of assumptions on utility functions that generate the intensive model described here. ${ }^{11}$ The link between this mobility elasticity and the elasticity of earnings with respect to tax rates of the usual labor supply model is investigated later on.

Proposition 2. At the optimum the optimal schedule is such that

(6) $\frac{T_{i}-T_{i-1}}{c_{i}-c_{i-1}}$

$$
=\frac{1}{\zeta_{i}}\left[\frac{\left(1-g_{i}\right) h_{i}+\left(1-g_{i+1}\right) h_{i+1}+\ldots+\left(1-g_{I}\right) h_{I}}{h_{i}}\right] .
$$

Equations (1) and (6) for $i=1,2, \ldots, I$ characterize the optimal tax levels $T_{i}$.

Proof. To derive optimal tax rules in this model, we consider as above a small perturbation of the optimal tax schedule. To derive a condition on the relative tax rates between jobs $i$ and $i-$ 1, I consider, as depicted on Figure IIIa, a small increase $d T$ in

11. Note that this specification with a discrete set of earnings outcomes rules out the bunching phenomenon that arises in the continuous Mirrlees [1971] model. As bunching is more a technical complication than an economically relevant feature of the Mirrlees model, there is no loss in ruling it out by definition. 
tax rates for jobs $i, i+1, \ldots, I ; d T_{i}=d T_{i+1}=\ldots=d T_{I}=$ $d T$. This tax change decreases $c_{i}-c_{i-1}$ by $d T$ but leaves unchanged all the other differences $c_{j}-c_{j-1}$ for $j \neq i$.

This tax change raises $\left[h_{i}+h_{i+1}+\ldots+h_{I}\right] d T$ additional taxes through the mechanical effect which are valued [(1 $\left.\left.g_{i}\right) h_{i}+\left(1-g_{i+1}\right) h_{i+1}+\ldots+\left(1-g_{I}\right) h_{I}\right] d T$ by the government. This change also induces $d h_{i}=-h_{i} \zeta_{i} d T /\left(c_{i}-c_{i-1}\right)$ individuals in job $i$ to switch to job $i-1$ reducing tax revenue by $\left(T_{i}-T_{i-1}\right) d h_{i}$. At the optimum, the sum of the two effects is zero implying equation (6). A formal proof of this result is provided in the Appendix.

QED

When the social weights $g_{i}$ are nonincreasing, equation (2) implies that $\left(1-g_{i}\right) h_{i}+\ldots+\left(1-g_{I}\right) h_{I} \geq 0$ for any $i>0$. Therefore, formula (6) implies that tax liability $T_{i}$ is increasing with $i .{ }^{12}$ In the intensive model, it is therefore never optimal to impose negative marginal tax rates. ${ }^{13}$ The reason for this result is depicted in Figure IIIb. If there is a negative marginal rate in some range (say between earnings levels $w_{i-1}$ and $w_{i}$ ), then, by slightly increasing this rate, as shown in Figure IIIb, the government reduces work incentives in that range but because the marginal tax rate is negative in that range, people who switch from $w_{i}$ to $w_{i-1}$ end up paying more taxes. Moreover, this small marginal tax rate increase allows the government to raise money from all taxpayers above $w_{i}$ which is also beneficial when the government values redistribution. ${ }^{14}$

To cast light on the marginal tax rate at the bottom, it is useful to use equation (2) to rewrite equation (6) for $i=1$ as

$$
\frac{T_{1}-T_{0}}{c_{1}-c_{0}}=\frac{1}{\zeta_{1}}\left[\frac{\left(g_{0}-1\right) h_{0}}{h_{1}}\right] \text {. }
$$

This equation shows that the higher the social weight on the unemployed $g_{0}$, the higher the marginal tax rate at the bottom. The intuition for this result is that the best way to make the lump sum transfer to the unemployed $-T_{0}$ as large as possible is to

12. Obviously, $c_{i}$ is increasing in $i$ because nobody would choose an occupation requiring more effort and providing less after-tax income.

13. As mentioned in the Introduction, this result was shown by Mirrlees [1971]. Seade [1982] described the precise assumptions needed to get the result and provided an intuition different from the one I give here.

14. Note that income effects, by creating a positive labor supply response for individuals with earnings above $w_{i}$ would reinforce the nonnegative marginal tax rate result (see Saez [2001]). 
target it to the unemployed by imposing large phasing-out tax rates at the bottom. When the government values an extra dollar to the unemployed less than an extra dollar uniformly distributed across all income groups, then $g_{0}<1$. Equation (7) shows that, in this case, $T_{1}<T_{0}$; that is, there is a negative marginal tax rate at the bottom producing an EITC schedule. However, the condition needed to obtain that result in the intensive model $\left(g_{0}<1\right)$ is drastic because it requires assuming that the unemployed are less deserving not only than the working poor but also than the average individual in the economy. In other words, it is much more difficult to make the case for an EITC program in the intensive model than in the extensive model. Therefore, with most redistributive tastes, the general conclusion of the pure intensive model is that redistribution should take place through a guaranteed income level that should be taxed away as income increases. The transfer program takes the form of a traditional Negative Income Tax and no Earned Income Tax Credit component should be included. ${ }^{15}$

\section{II.4. Mixing Extensive and Intensive Responses}

The previous subsections have illustrated the contrast between the intensive and extensive model for designing an optimal transfer scheme. However, the real world is obviously a mix of the two models. The goal of this subsection is thus to develop a model that incorporates both the extensive and the intensive margin of response in order to assess how these two effects interact and to perform numerical simulations.

In the pure extensive response model, the number of individuals in occupation $i$ depends on $c_{i}-c_{0}$. In the pure intensive model, the number of individuals in occupation $i$ depends on $c_{i}-$ $c_{i-1}$ and on $c_{i+1}-c_{i}$. In the general model with both extensive and intensive responses, the supply in each job $i$ is given by $h_{i}\left(c_{i}-c_{0}, c_{i+1}-c_{i}, c_{i}-c_{i-1}\right)$.

The optimal tax formulas in the mixed model are derived in the Appendix using the same methodology as above. The optimal tax formula expressed in terms of the intensive elasticities $\zeta_{i}$ and the participation elasticities $\eta_{i}$ is given by

15. Note finally that in the limiting case where everybody works $\left(h_{0}=0\right)$, equation (7) implies that $T_{1}=T_{0}$, and thus the marginal tax rate at the bottom is zero. This zero bottom result was proved in the continuous Mirrlees model by Seade [1977]. It requires everybody to work and thus does not seem to be relevant for practical tax policy recommendations. 


$$
\frac{T_{i}-T_{i-1}}{c_{i}-c_{i-1}}=\frac{1}{\zeta_{i} h_{i}} \sum_{j=i}^{I} h_{j}\left[1-g_{j}-\eta_{j} \frac{T_{j}-T_{0}}{c_{j}-c_{0}}\right] .
$$

Comparing equations (6) and (8), we see that the mixed model is identical to the intensive model with weights $g_{j}$ replaced by $\hat{g}_{j}=$ $g_{j}+\eta_{j}\left(T_{j}-T_{0}\right) /\left(c_{j}-c_{0}\right)$. Therefore, adding the participation margin amounts to attributing a higher welfare weight $\hat{g}_{j}$ to income groups that are prone to leave the labor force and that receive a lower transfer than the unemployed $\left(T_{j}>T_{0}\right)$.

Each of the two polar cases analyzed above can be obtained from equation (8) by letting either one of two elasticities ( $\eta$ or $\zeta$ ) tend to zero. As a result, if the participation elasticity is large relative to the earnings elasticity, the optimal schedule will have an EITC component with larger transfers for low income workers than for the unemployed. More precisely, because of the extensive margin of response, the pseudo weights $\hat{g}_{i}$ need not be decreasing even if the real weights $g_{i}$ are decreasing. As a result, optimal tax rates are not necessarily nonnegative as in the pure intensive model. On the other hand, if the elasticity $\eta$ is small relative to $\zeta$, then the optimal schedule will have nonnegative rates everywhere as in the standard intensive model.

The key difference between the intensive and the extensive model can be illustrated as follows. Starting from an NIT transfer system, suppose that the government contemplates increasing incentives for low skilled workers by reducing $T_{1}$. In the extensive model, the behavioral response is only on the participation margin and thus decreasing $T_{1}$ unambiguously increases labor supply. On the other hand, in the intensive model, in addition to inducing some of the unemployed to work in occupation 1, decreasing $T_{1}$ makes occupation 1 more attractive to workers in occupation 2 and thus reduces labor supply through that channel. As a result, increasing $T_{1}$ has ambiguous effects on labor supply in the intensive model. Alternatively, using the concepts of contract theory, the intuition can be formulated as follows. In the extensive model, increasing low income salaries does not tempt higher income earners to reduce their effort to imitate low income workers but does tempt the unemployed to start working. In the intensive model, increasing low income salaries tempts both the unemployed and higher income earners. A government contemplating increasing incentives at the bottom must precisely weigh the positive participation effect and the negative intensive labor 
supply effect. The models developed here give precise formulas to optimally trade off these two effects. The next section proposes a simple calibration of the model using a range of elasticities.

\section{EMPIRICAL CALIBRATION}

\section{III.1. Empirical Literature}

As mentioned in the Introduction, the empirical literature on labor supply and behavioral responses to taxes and transfers is large. Hausman [1985], Pencavel [1986], and Blundell and MaCurdy [1999] provide extensive reviews of the literature. Most studies find that the intensive labor supply elasticities of males are small. However, elasticities of labor force participation have been found to be much larger for some classes of the population such as the elderly, single mothers, or secondary earners. The model developed here is based on individual taxation, but most empirical studies focus instead on subgroups of the population such as prime male workers, wives, or single mothers and rarely estimate elasticities for the full population. As a result, it is difficult to calibrate elasticities very precisely from the existing empirical literature and the following discussion should be seen only as illustrative. For our simulations we need to pay special attention to elasticities of earnings and participation at the bottom of the income distribution. Two pieces of evidence are of particular interest.

First, in the late 1960 s, a series of Negative Income Tax experiments were implemented in the United States. These experiments in principle provide an ideal setup to estimate both participation and intensive elasticities of labor supply. Robins [1985] surveys the empirical results based on NIT experiments. Both intensive and extensive elasticities for males are small (around 0.2). The behavioral response for wives, single female heads, and the young is higher and concentrated along the participation margin. Participation elasticities are often in excess of 0.5 and sometimes close to $1 .^{16}$

Second, recent studies exploiting the recent increases in the EITC (see, e.g., Eissa and Liebman [1996] and Meyer and Rosen-

16. Ashenfelter [1978], for example, using data from the North Carolina-Iowa Rural Income Maintenance Experiment, reports elasticities for wives around 0.9, while elasticities for husbands are only around 0.2 . 
baum [2001]), have shown that the effect on participation of single female heads is substantial. ${ }^{17}$

To summarize, the literature suggests that participation elasticities at the low end of the income distribution may be large (perhaps above 0.5). Elasticities of earnings with respect to the tax rate are substantially smaller (perhaps around 0.25 ). The elasticity of participation at the middle and high end of the income distribution is very likely to be small. There is little consensus about the magnitude of intensive elasticities of earnings for middle income earners, although this elasticity is likely to be of modest size for middle income earners and higher for high income earners. Gruber and Saez [2000] summarize this literature and display empirical estimates between 0.25 and 0.5 for middle and high income earners.

\section{III.2. Numerical Simulations}

Numerical simulations are based on the discrete model mixing the extensive and intensive margin of behavioral response. In the simulations, I use a discrete grid of seventeen income levels. I describe in the Appendix the technical details of the simulations. It should be kept in mind that simulations display individual (and not family) tax and transfer schedules.

A number of parameters are crucial for tax schedule simulations.

First, the elasticity parameters summarizing the behavioral responses are prominent. As there is no strong consensus on the size of these parameters, I present simulations using a range of plausible parameter values. The values for the participation elasticity $\eta$ is taken as constant and equal to $0,0.5$ or 1 for incomes below $\$ 20,000$ and equal to 0 for incomes above $\$ 20,000$ because the participation elasticity is certainly small for middle and higher income earners.

The intensive elasticity $\zeta$ of the mobility model developed in Section II is not directly comparable to the classic intensive labor supply elasticity of the standard static labor supply model of Mirrlees [1971]. However, as described in the Appendix, the mobility elasticity $\zeta$ can simply be mapped into the standard labor supply elasticity of the usual model. As most empirical studies provide estimates of the standard elasticity, all simulations are

17. For example, Eissa and Liebman [1996] report participation elasticities for single mothers with low education around 0.6. 
presented in terms of the intensive labor supply elasticity from the standard model which is denoted by $\epsilon$. The intensive elasticity $\epsilon_{L}$ for incomes below $\$ 20,000$ is taken as constant and equal to 0 , 0.25 or 0.5 . The middle and high income (above $\$ 20,000$ ) elasticities $\epsilon_{H}$ is taken as constant and equal to 0.25 or 0.5 . All simulations have been carried out assuming no income effects. ${ }^{18}$

Second, the social welfare weights that summarize the redistributive tastes of the government may also affect the optimal level and patterns of taxation. I summarize the redistributive tastes of the government using a simple parametric form for the curve of marginal weights $g(c)=1 /\left(p \cdot c^{v}\right)$, where $p$ denotes the marginal value of public funds and $v$ is a scalar parameter. The higher is $v$, the higher are the redistributive tastes of the government. $v=+\infty$ corresponds to the Rawlsian criterion, while $v=0$ corresponds to redistributive tastes. Most of the simulations are presented with $v=1$ which represents fairly strong redistributive tastes. With $v=1$, the government values $N$ times less marginal consumption when disposable income is multiplied by $N$. Note that this calibration always produces weights $g_{i}$ decreasing with $i$ and does not discriminate against the unemployed.

Third, the income distribution is calibrated using the empirical yearly earnings distribution from the March 1997 Current Population Survey (CPS). Annual earnings are defined as total wage income and self-employment income earned in year 1996. All dollar values are in 1996 dollars. I limit the sample to individuals aged 18 to 60 , and I exclude students. The rate of nonlabor force participation (zero yearly earnings reported) for this group is slightly below 15 percent. Obviously, the distribution of earnings is endogenous because it is affected by taxes and transfers. As described in the Appendix, the earnings distribution functions $h_{i}$ are chosen to be compatible with the specified elasticities and calibrated so as to match the empirical earnings distribution when a simple approximation to the current $\mathrm{U}$. S. tax and transfer system is in place.

Last, I specify the exogenous revenue requirement of the government $H$ as follows. I assume that the government wants to collect the same amount that is actually collected with the income tax (state and federal) net of redistribution done with the earned

18. Simulations including income effects in the pure extensive model of subsection II. 2 have been performed. Income effects have little effect on the size and shape of the optimal transfer program but can have a substantial effect on the percentage of unemployed workers. 

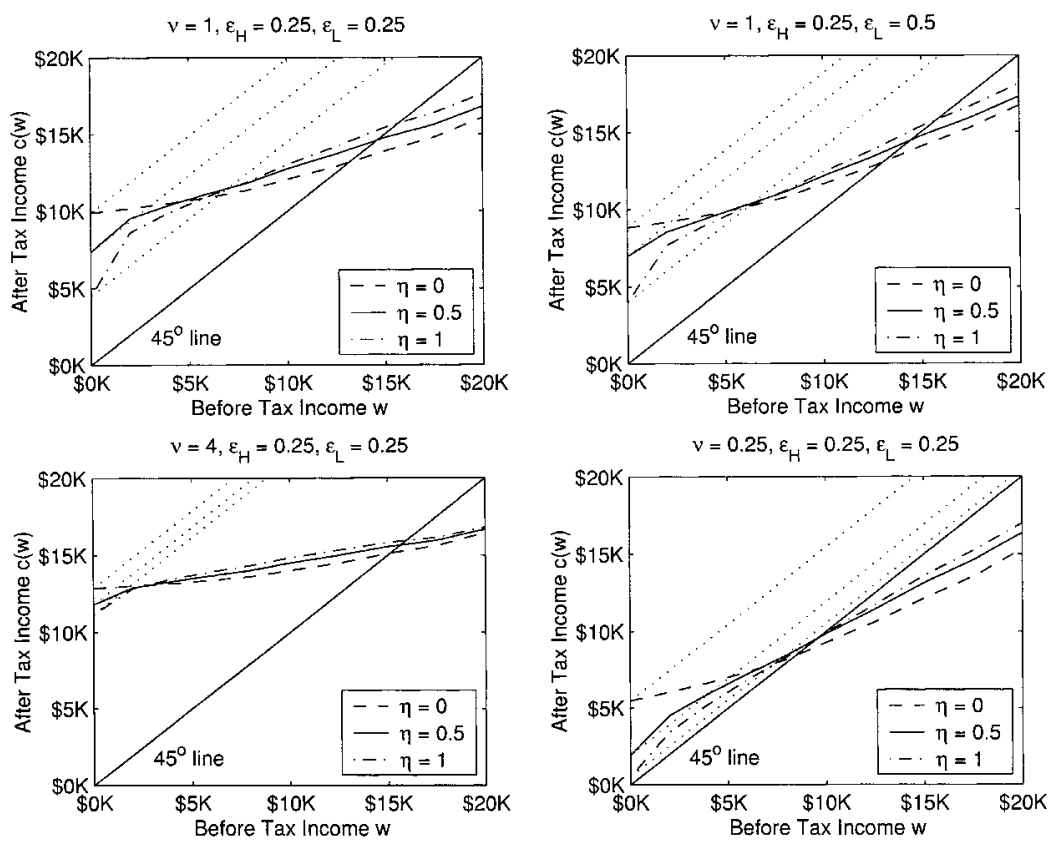

FIGURE IV

Optimal Tax Schedules

income tax credit, and other cash transfers such as TANF or Food Stamps. This amount is around $\$ 8000$ per household, implying an average annual tax per adult around $\$ 5000$. Therefore, in the simulations, $H$ is taken as equal to $\$ 5000$. Therefore, the tax schedules presented are roughly comparable to the actual welfare and income tax schedule.

The results of numerical simulations are presented in the four panels of Figure IV and in Tables I and II. Figure IV displays optimal disposable income schedules $c(w)=w-T(w)$ as a function of earnings $w$. Even though optimal tax schedules are simulated for the entire income distribution, Figure IV focuses on the part below $\$ 20,000$ (which covers about the bottom half of the population) because this is the part that is of primary interest in this paper. The 45-degree line gives the benchmark schedule with no tax or subsidy. Each figure displays the optimal schedules for three values of the participation elasticity $\eta(0,0.5$, and 1$)$ and fixed values of the intensive elasticities for high and low incomes 


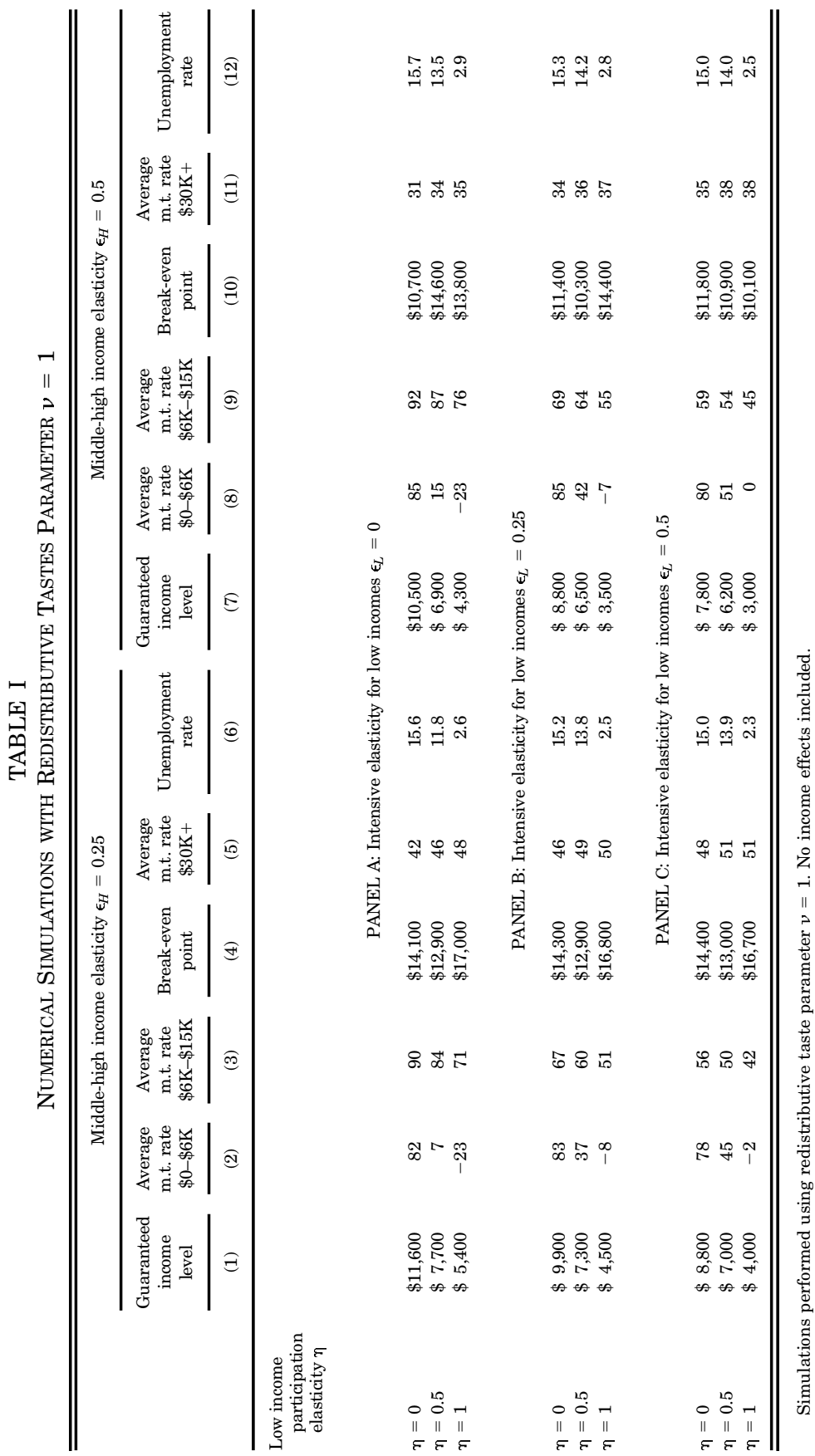


TABLE II

Numerical Simulations with Varying Redistributive Tastes

\begin{tabular}{|c|c|c|c|c|c|c|}
\hline & \multicolumn{6}{|c|}{ Elasticity $\epsilon_{H}=0.25$, Elasticity $\epsilon_{L}=0.25$} \\
\hline & $\begin{array}{c}\text { Guaranteed } \\
\text { income } \\
\text { level }\end{array}$ & $\begin{array}{c}\text { Average } \\
\text { m.t. rate } \\
\$ 0-\$ 6 \mathrm{~K}\end{array}$ & $\begin{array}{c}\text { Average } \\
\text { m.t. rate } \\
\$ 6 \mathrm{~K}-\$ 15 \mathrm{~K}\end{array}$ & $\begin{array}{c}\text { Break-even } \\
\text { point }\end{array}$ & $\begin{array}{l}\text { Average } \\
\text { m.t. rate } \\
\$ 30 \mathrm{~K}+\end{array}$ & $\begin{array}{l}\text { Unemployment } \\
\text { rate }\end{array}$ \\
\hline & (1) & (2) & (3) & (4) & (5) & (6) \\
\hline \multicolumn{7}{|c|}{$\begin{array}{l}\text { Low income } \\
\text { participation } \\
\text { elasticity } \eta\end{array}$} \\
\hline \multicolumn{7}{|c|}{ PANEL A: Low redistributive tastes parameter $v=0.25$} \\
\hline$\eta=0$ & $\$ 5,500$ & 68 & 47 & $\$ 9,600$ & 27 & 14.6 \\
\hline$\eta=0.5$ & $\$ 1,900$ & 12 & 34 & $\$ 8,500$ & 30 & 7.7 \\
\hline$\eta=1$ & $\$ 540$ & -5 & 25 & $\$ 8,300$ & 31 & 2.7 \\
\hline \multicolumn{7}{|c|}{ PANEL B: Medium redistributive tastes parameter $v=1$} \\
\hline$\eta=0$ & $\$ 9,900$ & 83 & 67 & $\$ 14,300$ & 46 & 15.2 \\
\hline$\eta=0.5$ & $\$ 7,300$ & 37 & 60 & $\$ 12,900$ & 49 & 13.8 \\
\hline$\eta=1$ & $\$ 4,500$ & -8 & 51 & $\$ 16,800$ & 50 & 2.5 \\
\hline \multicolumn{7}{|c|}{ PANEL C: High redistributive tastes parameter $v=4$} \\
\hline$\eta=0$ & $\$ 12,900$ & 92 & 81 & $\$ 17,400$ & 62 & 16.0 \\
\hline$\eta=0.5$ & $\$ 11,800$ & 69 & 79 & $\$ 16,800$ & 63 & 26.0 \\
\hline$\eta=1$ & $\$ 11,200$ & 54 & 79 & $\$ 16,600$ & 64 & 27.2 \\
\hline
\end{tabular}

Simulations performed using low income intensive elasticity $\epsilon_{L}=0.25$ and high income elasticity $\epsilon_{H}=0.25$.

$\left(\epsilon_{L}\right.$ and $\left.\epsilon_{L}\right)$ and the redistributive tastes (parameter $\boldsymbol{v}$ ). Income effects are assumed away in all simulations.

In the top-left panel, $\epsilon_{L}=0.25, \epsilon_{H}=0.25$, and $\nu=1$. This panel shows that increasing $\eta$ substantially affects the shape of the optimal transfer program. With $\eta=0$, the program is a traditional NIT with a substantial guaranteed income (\$9900) and high phasing-out rates (around 70 percent). However, when $\eta$ increases, an EITC bubble appears at the low end. The guaranteed income is reduced $(\$ 4500$ for $\eta=1)$, and earnings are slightly subsidized over the income range $\$ 0$ to $\$ 6000$. From $\$ 6000$ to $\$ 15,000$, the transfer is taxed away at a high rate (in excess of 50 percent).

The top-right panel of Figure IV displays the same graphs with a higher intensive elasticity for low incomes $\epsilon_{L}=0.5$. 
Increasing $\epsilon_{L}$ reduces the size of the EITC bubble. It also slightly decreases the guaranteed income level and decreases the phasing-out rate.

The bottom panels of Figure IV consider variations in the redistributive parameter $v$. In the bottom-left panel, $v=4$, which represents extremely strong redistributive tastes close to the Rawlsian case ${ }^{19}$ Relative to the top-left panel benchmark, the size of the guaranteed income is substantially higher (around $\$ 12,000$ ), the phasing-out rate is very high (around 80 percent), and the EITC bubble has completely disappeared: the elasticity of participation $\eta$ has little effect on the optimal schedule. In the bottom-right panel, $v=0.25$, which represents a very low taste for redistribution. ${ }^{20}$ Relative to the top-left panel, the guaranteed income is very small (less than $\$ 2,000$ for $\eta=0.5,1$ ). Both the EITC bubble and the phasing-out rates are small.

Tables I and II summarize the optimal schedules for a wider range of parameters. Optimal schedules are summarized by five numbers: first, the guaranteed income level $-T(0)$ that is provided to the unemployed; second, the average marginal tax rate from $\$ 0$ to $\$ 6000$ ([T(6000) - T(0)]/6000) which measures the tax distortion at the lowest end of the earnings distribution; third, the average marginal tax rate from $\$ 6000$ to $\$ 15,000$ ([T(15,000) - T(6000)]/[15,000 - 6000]) which measures the phasing-out rate of the transfer program; fourth, the break-even point which is the income level at which transfers are equal to zero $(T(w)=0)$ is presented; fifth, the average marginal tax rate from $\$ 30,000$ to $\$ 100,000$ which measures the tax burden for middle and high income earners. Finally, the level of unemployment induced by the optimal transfer program is reported.

As shown in Table I, a higher elasticity $\epsilon_{H}$ for middle and high income earners reduces the optimal rates for high incomes and thus the size of the optimal transfer program. When $\eta$ is high, the level of transfers significantly affects the unemployment rate and hence the cost of the transfer program. With $\eta=1$, the optimal transfer program reduces the nonlabor force participation rate to an unrealistic rate less than 3 percent.

Table II investigates the effect of the redistributive taste $v$. The cases $v=0.25, v=1$, and $v=4$ are considered in Panels A,

19. With $v=4$, the government values sixteen times less marginal consumption when disposable income doubles.

20 . With $v=0.25$, the government values only two times less marginal consumption when disposable income is multiplied by sixteen. 
B, and C. Unsurprisingly, higher redistributive tastes lead to a larger guaranteed income level and higher phasing-out rates and higher rates for middle and high incomes.

From the empirical literature, we can consider the case $\eta=$ $0.5, \epsilon_{L}=0.25$, and $\epsilon_{H}=0.25$ as a plausible benchmark. In that case with $v=1$, the optimal transfer program should consist of a guaranteed income level with a modest tax rate for the first few thousands dollars of earned income (tax rate around 10 percent for the first $\$ 4000$ earned). The transfer income should then be taxed at fairly high rates farther up the income distribution (tax rate around 60 percent from $\$ 4000$ to $\$ 15,000$ ). Tax rates should then be lower (around 50 percent) for middle and high income earners. The size of the guaranteed income level is relatively large at $\$ 7300$. Therefore, the simulations suggest that combining a sizable Negative Income Tax program with a tax exemption for the first $\$ 5000$ of annual earnings might be a desirable way to redistribute toward the disadvantaged. The guaranteed income provides income support for the really needy, and the earnings exemption does not too severely discourage work participation by people with low earnings potential.

The model used in the paper is of course a crude approximation of the actual economic situation, and therefore simulations should be regarded as illustrative only. It is nonetheless interesting to speculate what type of elasticity and redistributive parameters could justify the current structure of the U. S. transfer program policy. The current U. S. system applies very different tax schedules depending on the family status of the households. Two-parent low income families are not in general eligible for welfare programs and thus can only collect EITC benefits implying that they face negative marginal rates of -40 percent over the first $\$ 10,000$ dollars of household earnings and tax rates around 25 percent on the next $\$ 10,000$ of earnings. However, the husband in a two-parent family almost always works; thus, the EITC is rarely effective in encouraging work participation for those families. As argued by Eissa and Hoynes [1998], the EITC program might well discourage female labor participation because of the extra tax rate in the phasing-out region.

Single-parent families are also entitled to TANF and Food Stamps which are NIT-type programs. This programs provide a basic support (around $\$ 10,000$ but with large variation across states). The sum of Individual income taxation, EITC, TANF, and Food Stamps generate tax rates around 20 percent for the first 
$\$ 9000$ of earnings but much higher rates, around 70 percent, for the next $\$ 9000$ of earnings. As discussed above, most estimates suggest that participation elasticities for these groups are large (in excess of 0.5). It is striking to see how close this schedule is to our benchmark simulation result $\left(\eta=0.5, \epsilon_{H}=\epsilon_{L}=0.25\right.$, and $v=1$ ).

Finally, families or individuals with no children are entitled to very few benefits. This is a well-known gap in the U. S. welfare structure that is not justified in the type of model we have considered. Therefore, the current U. S. welfare comes fairly close to our simulation results only for single-parent families. This group, however, represents a large fraction of the population in need of income support.

The logic of the U. S. transfer system is often explained as follows. The government provides NIT income transfer programs to those who cannot work such as the disabled with Disability Insurance, the old with Supplemental Social Security Income, and single mothers with TANF. The rest of the population is considered as able to work and is helped mostly with the EITC if they do work and support children. This coarse rule for redistribution can be justified theoretically if those deemed not able to work are indeed unresponsive to incentives, in which case a guaranteed income with a 100 percent rate is optimal. However, numerous empirical studies have suggested that labor supply in these groups is responsive to incentives. An EITC for those who can work is justified if they respond mostly through the extensive margin.

\section{Conclusion}

This paper has shown that the nature of labor supply responses to taxes and transfers is critical to design optimal income transfer programs. If the behavioral response is mainly along the intensive margin, then the optimal program is a classical Negative Income Tax program with a large guaranteed income level which is taxed away at high rates. However, if the behavioral response is concentrated along the extensive or labor force participation margin, then the optimal program is an Earned Income Tax Credit with a smaller guaranteed income level and transfers that increase with earnings at low income levels. Formulas for optimal tax rates have been derived in terms of the behavioral elasticities and the redistributive tastes of the government. 
The main lesson from the numerical simulations is that the optimal program is fairly sensitive to the size of the participation elasticity. When the participation elasticity is zero, the optimal program is a large Negative Income Program with a guaranteed income in excess of $\$ 10,000$ and a high phasing-out rate (around 70 percent). However, if the participation elasticity is substantial, then the guaranteed income level should be lower, but the first $\$ 5000$ to $\$ 7000$ should be exempted from taxation (or even slightly subsidized). The guaranteed income should then be taxed at a fairly high rate for incomes between $\$ 6000$ and $\$ 15,000$. It is therefore critical to carefully distinguish participation and intensive elasticities in empirical studies. If the participation elasticity is large, then very strong redistributive tastes are needed to obtain an optimal guaranteed income level above the poverty level. The combined EITC and U. S. welfare system for single mothers is close to our optimal simulated schedules if, as evidenced by empirical studies, participation elasticities are substantial.

The present model could be extended in four directions. First, the paper considered a model of individual labor supply decisions. An important feature that is missing is the secondary earner labor supply decision. There is ample empirical evidence that the labor participation decision of wives is very elastic. This suggests that a tax on total household earnings as in the United States might be inefficient. At the same time, a tax on individuals, as in the United Kingdom, is more efficient but also less equitable because total household income is a better indicator of well-being than individual income. The secondary earner problem raises an interesting and difficult optimal income tax problem which could be tackled using the methods developed in this paper. Note also that participation elasticities are likely to be correlated with fixed costs of work. As a result, single-headed families with young children, for example, are more likely to be very elastic on the participation margin and should be encouraged to work through EITC type programs.

Second, there is evidence in the labor literature that longterm unemployment experiences may have an adverse effect on human capital and thus on subsequent wages. This problem is especially acute in Europe. This extra cost of unemployment has not been taken into account in the present paper. Plausibly, if this extra cost is high, then the optimal policy should be tilted even more toward EITC-type programs and away from NIT programs. 
An important element to consider when designing the optimal policy in this case is whether individuals fully internalize the extra cost of unemployment.

Third, using empirical elasticities, it would be interesting to infer the social weights $g_{i}$ that make the actual U. S. tax and transfer system optimal. Even if the government does not explicitly maximize welfare, it may be interesting to know what are the implicit weights that the government is using. For example, if some of the weights appear to be negative, then the tax schedule is not second-best Pareto efficient. ${ }^{21}$

Last, this study has been carried out in a timeless economy and has ignored the important question of the time period on which tax liability is computed. As discussed earlier on, this implicit time period obviously affects the relative scope of extensive versus intensive margin. Therefore, introducing time raises the important but difficult question on the optimal period that should be taken into account to compute tax liability. Relatively little work has been done on this subject. ${ }^{22}$ It might be the case that the time dimension for assessing optimal tax and transfers programs is important and that applying EITC programs on a monthly or quarterly basis could be more effective than an annual basis. This largely underexplored issue is left for future research.

\section{APPENDIX}

\section{Formal Model}

Individuals are indexed by $m \in M$ being a (possibly multidimensional) set of measure one. The measure of individuals on $M$ is denoted by $d v(m)$. Individual $m \in M$ has a utility function $u^{m}\left(c_{i}, i\right)$ defined on after-tax income $c_{i} \geq 0$ and job choice $i=$ $0, \ldots, I$. Each individual chooses $i$ to maximize $u^{m}\left(c_{i}, i\right)$, where $c_{i}=w_{i}-T_{i}$ is the after-tax reward in occupation $i$. The labor supply decision of individual $m$ is denoted by $i^{*} \in\{0,1, \ldots, I\}$. For a given tax and transfer schedule $\left(c_{0}, \ldots, c_{I}\right)$, the set $M$ is partitioned into $I+1$ subsets, $M_{0}, \ldots, M_{I}$, defining the sets of individuals choosing, respectively, each of the occupations

21. This analysis has been used frequently in the commodity taxation literature where it is known as the inverse optimum problem [Ahmad and Stern 1984] but has never been applied to the transfer program problem.

22 . Vickrey is the economist who has studied the issue the most carefully. He advocated a system of lifetime taxation (see Vickrey [1947]). 
$0, \ldots, I$. The fraction of individuals choosing occupation $i$, denoted by $h_{i}\left(c_{0}, \ldots, c_{I}\right)$ is simply the measure of set $M_{i}$. It is assumed that the tastes for work embodied in the individual utilities are regularly distributed so that the aggregate functions $h_{i}$ are differentiable. The government chooses $\left(T_{0}, \ldots, T_{I}\right)$ so as to maximize welfare:

$$
W=\int_{M} \mu^{m} u^{m}\left(w_{i^{*}}-T_{i^{*}, i^{*}}\right) d v(m),
$$

where $\mu^{m}$ are positive weights and subject to the budget constraint (1). I denote by $p$ the multiplier of this constraint. Even though the population is potentially very heterogeneous, as possible work outcomes are finite in number, the maximization problem is a simple finite dimensional problem. The first-order condition with respect to $T_{i}$ is

$$
-\int_{M_{i}} \mu^{m} \frac{\partial u^{m}\left(c_{i^{*}}, i^{*}\right)}{\partial c_{i}} d \nu(m)+p\left[h_{i}-\sum_{j=0}^{I} T_{j} \frac{\partial h_{j}}{\partial c_{i}}\right]=0 .
$$

When obtaining (9), it is important to note that, because of the envelope theorem, the effect of an infinitesimal change in $c_{i}$ has no first-order effect on welfare for individuals moving in or out of occupation $i$, and therefore there is no need to take into account, in the first term of (9), the effect of a change of $c_{i}$ on the set $M_{i}$. I define the marginal social welfare weight for occupation $i$ as

$$
g_{i}=\frac{1}{p h_{i}} \int_{M_{i}} \mu^{m} \frac{\partial u^{m}\left(c_{i^{*}}, i^{*}\right)}{\partial c_{i}} d \nu(m) .
$$

As explained in the text, this weight represents the dollar equivalent value for the government of distributing an extra dollar uniformly to individuals working in occupation $i$. Obviously, the weights $g_{i}$ vary with the tax schedule $\left(c_{0}, \ldots, c_{I}\right)$. In welfare economics, the primitive parameters are the utility functions $u^{m}$ and weights $\mu^{m}$, which generate an endogenous set of marginal weights $g_{i}\left(c_{0}, \ldots, c_{I}\right)$. However, the weights $g_{i}$ have a direct and more transparent interpretation than the primitive weights $\mu^{m}$. That is why, in the simulations and as discussed in the text, we directly calibrate the weights functions as $g_{i}=g\left(c_{i}\right) / p$ without specifying the primitive weights $\mu^{m}$. Obviously, it would be pos- 
sible in each case to find a set of weights $\mu^{m}$ that generate weights $g_{i}$ equal to the calibrated weights $g\left(c_{i}\right) / p$ at the optimum schedule. Using definition (10), the first-order condition (9) can be rewritten as

$$
\left(1-g_{i}\right) h_{i}=\sum_{j=0}^{I} T_{j} \frac{\partial h_{j}}{\partial c_{i}} .
$$

With no income effects, $h_{j}\left(c_{0}+R, \ldots, c_{I}+R\right)=$ $h_{j}\left(c_{0}, \ldots, c_{I}\right)$. Thus, $\Sigma_{i} \partial h_{j} / \partial c_{i}=0$, and therefore, summing equation (11) over all $i=0, \ldots, I$, one obtains equation (2).

\section{The Extensive Model}

Within the general framework developed above, the extensive model can be obtained by assuming that each individual can work only in one occupation or be unemployed. This can be embodied in the individual utility functions by assuming that $u^{m}\left(c_{j}, j\right)=-\infty$ for all occupations $j \geq 1$ except the one corresponding to the skill of the individual. This structure implies that the function $h_{i}$ depends only on $c_{0}$ and $c_{i}$ for $i>0$. As a result, and using the fact that $\partial h_{i} / \partial c_{i}+\partial h_{0} / \partial c_{i}=0$, equation (11) becomes

$$
\left(1-g_{i}\right) h_{i}=T_{i} \frac{\partial h_{i}}{\partial c_{i}}+T_{0} \frac{\partial h_{0}}{\partial c_{i}}=\left(T_{i}-T_{0}\right) \frac{\partial h_{i}}{\partial c_{i}} .
$$

Using the definition (3) of $\eta_{i}$, one immediately obtains (4) in Proposition 1.

\section{The Intensive Model}

The intensive model can be obtained by assuming that each individual can only work in two adjacent occupations $i$ and $i+1$ for a given $i$ embodied in the individual utility $u^{m}$. This implies that the function $h_{i}$ depends only on $c_{i+1}, c_{i}$, and $c_{i-1}$. Assuming no income effects, with a slight abuse of notation, $h_{i}$ can be expressed as $h_{i}\left(c_{i+1}-c_{i}, c_{i}-c_{i-1}\right)$. In this context, equation (11) becomes

$$
\begin{aligned}
\left(1-g_{i}\right) h_{i}=-T_{i+1} \frac{\partial h_{i+1}}{\partial\left(c_{i+1}-c_{i}\right)}- & T_{i} \frac{\partial h_{i}}{\partial\left(c_{i+1}-c_{i}\right)} \\
+ & T_{i} \frac{\partial h_{i}}{\partial\left(c_{i}-c_{i-1}\right)}+T_{i-1} \frac{\partial h_{i-1}}{\partial\left(c_{i}-c_{i-1}\right)} .
\end{aligned}
$$


Using the fact that $\partial h_{i+1} / \partial\left(c_{i+1}-c_{i}\right)=-\partial h_{i} / \partial\left(c_{i+1}-c_{i}\right)$ and rearranging, we obtain

$$
\left(1-g_{i}\right) h_{i}=-\left(T_{i+1}-T_{i}\right) \frac{\partial h_{i+1}}{\partial\left(c_{i+1}-c_{i}\right)}+\left(T_{i}-T_{i-1}\right) \frac{\partial h_{i}}{\partial\left(c_{i}-c_{i-1}\right)} .
$$

Using the definition (5) of $\zeta_{i}$ and summing this equation over $i$, $i+1, \ldots, I$, one obtains (6) in Proposition 2.

\section{Optimal Tax Formula in the General Model}

The formal mixed model can be obtained by assuming that each individual has a choice between three occupations $0, i$, and $i+1$ for some $i$. Using the methods developed above, it is possible to obtain formula (8) in the text. Alternatively, the optimal tax formula can be derived as in subsection II.3 by considering a small change $d T$ in the tax rates for jobs $i, i+1, \ldots, I: d T_{i}=$ $d T_{i+1}=\ldots=d T_{I}=d T$. This tax change raises $\left[h_{i}+h_{i+1}+\right.$ $\left.\ldots+h_{I}\right] d T$ additional taxes through the mechanical effect which are valued $\left[\left(1-g_{i}\right) h_{i}+\left(1-g_{i+1}\right) h_{i+1}+\ldots+(1-\right.$ $\left.\left.g_{I}\right) h_{I}\right] d T$ by the government.

As in subsection II.3, this tax change decreases $c_{i}-c_{i-1}$ by $d T$ and leaves unchanged all the other differences $c_{j}-c_{j-1}$ which induces $d h_{i}=-h_{i} \zeta_{i} d T /\left(c_{i}-c_{i-1}\right)$ individuals in job $i$ to switch to job $i-1$ reducing tax revenue by $\left(T_{i}-T_{i-1}\right) d h_{i}=-\left(T_{i}-\right.$ $\left.T_{i-1}\right) h_{i} \zeta_{i} d T /\left(c_{i}-c_{i-1}\right)$.

This tax change also changes all the differences $c_{j}-c_{0}$ for $j \geq i$ and thus induces a number $-h_{j} \eta_{j} d T /\left(c_{j}-c_{0}\right)$ of individuals in each occupation $j \geq i$ to become unemployed. Therefore, the total behavioral cost due to movements in and out of unemployment is equal to $-d T \sum_{j \geq i}\left(T_{j}-T_{0}\right) h_{j} \eta_{j} /\left(c_{j}-c_{0}\right)$. At the optimum, the sum of these effects is zero, implying equation (8) in the text.

\section{Relating $\zeta_{i}$ and $\epsilon_{i}$}

In the classical model of labor supply with no income effects, labor supply responses are measured by the elasticity of earnings with respect to one minus the marginal tax rate $\epsilon=[(1-$ $\tau) / w] \partial w / \partial(1-\tau)$. In the discrete model of subsection II.3, I can define an implicit marginal tax rate $\tau_{i}$ between occupations $i$ and $i-1$ as, $\tau_{i}=\left(T_{i}-T_{i-1}\right) /\left(w_{i}-w_{i-1}\right)$ or equivalently $1-\tau_{i}=$ $\left(c_{i}-c_{i-1}\right) /\left(w_{i}-w_{i-1}\right)$. 
Consider, as seen in subsection II.3, a small change $d T$ in all tax levels $T_{j}$ for $j \geq i$. By definition of the implicit marginal tax rate $\tau_{i}$, this tax change is equivalent to a change in the marginal rate $\tau_{i}$ equal to $d \tau_{i} /\left(1-\tau_{i}\right)=d T /\left(c_{i}-c_{i-1}\right)$.

Using the mobility elasticity $\zeta_{i}$, this small tax change induces a loss in tax revenue equal to

$$
-\left(T_{i}-T_{i-1}\right) h_{i} \zeta_{i} \frac{d T}{c_{i}-c_{i-1}}=-\tau_{i} h_{i}\left(w_{i}-w_{i-1}\right) \zeta_{i} \frac{d \tau_{i}}{1-\tau_{i}} .
$$

In the classic labor supply model, by definition of the earnings elasticity $\epsilon_{i}$, this tax change reduces earnings of the individuals with income $w_{i}$ by $d w=-\boldsymbol{\epsilon}_{i} w_{i} d \tau_{i} /\left(1-\tau_{i}\right)$. As there are $h_{i}$ individuals with income $w_{i}$, the total effect on tax revenue is equal to $\tau_{i} h_{i} d w$ which can be written as

$$
-\tau_{i} w_{i} h_{i} \epsilon_{i} \frac{d \tau_{i}}{1-\tau_{i}} .
$$

Therefore, comparing (12) and (13), we see that the two models produce the same behavioral response when

$$
\zeta_{i}\left(w_{i}-w_{i-1}\right)=\epsilon_{i} w_{i} .
$$

This expression defines the mapping between the mobility elasticity $\zeta$ and the standard elasticity $\epsilon$.

\section{Numerical Simulations}

The numerical simulations are performed using the empirical earnings distribution. The data used to calibrate the earnings distribution are annual individual earnings data from the March 1997 Current Population Survey. Earnings are for year 1996 and are expressed in current dollars. The sample is limited to nonstudent individuals aged 18 to 60 . Earnings are defined as the sum of total wage income and self-employment income. The simulations are performed using the discrete model of subsection II.4. The empirical earnings distribution is approximated using a discrete grid of earnings levels that are displayed in Table III. For each earning level $w_{i}$, the corresponding density weight $h_{i}^{0}$ is computed as the fraction of individuals whose earnings fall in the range $\left[w_{i}-\left(w_{i}-w_{i-1}\right) / 2 ; w_{i}+\left(w_{i+1}-w_{i}\right) / 2\right]$. The estimated density weights $h_{i}^{0}$ along with the cumulative distribution are reported in Table III. The nonlabor force participation rate is equal to 14.2 percent. 
TABLE III

Empirical EARnings Distribution CaLibration

\begin{tabular}{|c|c|c|c|}
\hline \multicolumn{2}{|c|}{ Income levels } & \multirow{2}{*}{$\frac{\text { Density weights (in percent) }}{(2)}$} & \multirow{2}{*}{$\frac{\text { Cumulative distribution }}{(3)}$} \\
\hline & (1) & & \\
\hline$\$$ & 0 & 14.2 & 14.2 \\
\hline$\$$ & 2,000 & 3.3 & 17.5 \\
\hline$\$$ & 4,000 & 2.7 & 20.2 \\
\hline$\$$ & 6,000 & 2.8 & 23.0 \\
\hline$\$$ & 8,000 & 3.0 & 26.0 \\
\hline$\$$ & 10,000 & 4.8 & 30.8 \\
\hline$\$$ & 12,500 & 5.2 & 36.0 \\
\hline$\$$ & 15,000 & 6.5 & 42.5 \\
\hline$\$$ & 17,500 & 4.7 & 47.2 \\
\hline$\$$ & 20,000 & 8.2 & 55.4 \\
\hline$\$$ & 25,000 & 9.8 & 65.2 \\
\hline$\$$ & 30,000 & 16.4 & 81.6 \\
\hline & 50,000 & 14.5 & 96.1 \\
\hline & 100,000 & 3.9 & 100.0 \\
\hline
\end{tabular}

Column (2) indicates the density weights corresponding to each income level in column (1). The earnings distribution is computed from March 1997 CPS data. The base year for earnings is 1996 (incomes expressed in current dollars).

Sample are restricted to nonstudent individuals aged 18-60.

Earnings are defined as total wage income plus self-employment income.

Column (3) displays the cumulative distribution.

The system consists of $I+2$ simultaneous equations (2), (1), and (8) for $i=1, \ldots, I$. The welfare weights are $g_{i}=1 /\left(p \cdot c_{i}^{v}\right)$, where $p$ is the marginal value of public funds and $v$ is the redistributive tastes parameter. There are $I+2$ unknowns, the tax levels $T_{i}$ for $i=0,1, \ldots, I$ and the marginal value of public funds $p$. The system has $I+2$ equations and $I+2$ unknowns and thus yields in practice a unique solution.

The main complication of simulations comes from the endogeneity of the density weights $h_{i}$. The density weights $h_{i}$ are endogenous because the distribution of earnings and the unemployment level are affected by taxes and transfers. Formally, subsection II.4 has shown that the functional form of the density weights is $h_{i}\left(c_{i}-c_{0}, c_{i+1}-c_{i}, c_{i}-c_{i+1}\right)$. In principle, the weights $h_{i}$ should satisfy two conditions. First, the functional form of the weights $h_{i}$ should be chosen so as to be compatible with the structure of behavioral elasticities $\eta_{i}$ and $\zeta_{i}$ defined in equations (3), and (5)). Second, the weights $h_{i}$ should coincide with the empirical weights $h_{i}^{0}$ when the tax schedule $\left(T_{i}, i=\right.$ $0,1, \ldots, I)$ is equal to the actual schedule $\left(T_{i}^{0}, i=0,1, \ldots, I\right)$. 
However, it is impossible to find functions $h_{i}\left(c_{i}-c_{0}, c_{i+1}-\right.$ $c_{i}, c_{i}-c_{i+1}$ ) that satisfy equations (3), and (5) for constant elasticities $\eta_{i}$, and $\zeta_{i}$ for all possible values of $c_{0}$ and $c_{i}, i=0$, $1, \ldots, I$. Therefore, in the simulations, I ignore the effect of the intensive behavioral response on $h_{i}$. The density weights are taken as

$$
h_{i}=h_{i}^{0} \cdot\left(\frac{c_{i}-c_{0}}{c_{i}^{0}-c_{0}^{0}}\right)^{n_{i}}
$$

where $c_{i}^{0}, i=0,1, \ldots, I$ is the actual after-tax schedule. The schedule $c_{i}^{0}$ used in simulations is a very simplified approximation of the real schedule. The real schedule is approximated with a linear tax schedule with constant tax rate of 40 percent and a guaranteed income $c_{0}^{0}=\$ 6000$. Sensitivity analysis shows that the optimal schedules are not significantly affected when other assumptions for the actual schedule $c_{i}^{0}$ are made.

\section{HARVARD UNIVERSITY AND NBER}

\section{REFERENCES}

Ahmad, Ehtisham, and Nicholas Stern, "The Theory of Reform and Indian Indirect Taxes," Journal of Public Economics, XXV (1984), 259-298.

Akerlof, George, "The Economics of Tagging as Applied to the Optimal Income Tax," American Economic Review, LXVIII (1978), 8-19.

Ashenfelter, Orley, "The Labor Supply Response of Wage Earners," in J. Palmer and J. Pechman, eds., Welfare in Rural Areas (Washington, DC: The Brookings Institution, 1978).

Besley, Timothy, and Stephen Coate, "Workfare versus Welfare: Incentive Arguments for Work Requirements in Poverty Alleviation Programs," American Economic Review, LXXXII (1992), 249-261.

Besley, Timothy, and Stephen Coate, "The Design of Income Maintenance Programmes," Review of Economic Studies, LXII (1994), 187-221.

Blundell, Richard, and Thomas MaCurdy, "Labor Supply: A Review of Alternative Approaches," in O. Ashenfelter and D. Card, eds., Handbook of Labor Economics, Volume IIIA (Amsterdam: North-Holland, 1999).

Bound, John, "The Health and Earnings of Rejected Disability Insurance Applicants," American Economic Review, LXXIX (1989), 482-503.

_, "The Health and Earnings of Rejected Disability Insurance Applicants: Reply," American Economic Review, LXXXI (1991), 1427-1434.

Diamond, Peter, "Income Taxation with Fixed Hours of Work," Journal of Public Economics, XIII (1980), 101-110.

Diamond, Peter, L. Helms, and James Mirrlees, "Optimal Taxation in a Stochastic Economy: A Cobb-Douglas Example," Journal of Public Economics, XIV (1980), 1-29.

Diamond, Peter, and James Mirrlees, "A Model of Optimal Social Insurance with Variable Retirement," Journal of Public Economics, X (1978), 295-336.

Eissa, Nada, and Hilary Hoynes, "The Earned Income Tax Credit and the Labor Supply of Married Couples," NBER Working Paper No. 6856, 1998.

Eissa, Nada, and Jeffrey Liebman, "Labor Supply Response to the Earned Income Tax Credit," Quarterly Journal of Economics, CXI (1996), 605-637. 
Gruber, Jonathan, and Emmanuel Saez, "The Elasticity of Taxable Income: Evidence and Implications," NBER Working Paper No. 7512, 2000.

Hausman, Jerry, "Taxes and Labor Supply," in A. J. Auerbach and M. Feldstein, eds., Handbook of Public Economics, Volume I (Amsterdam: North-Holland, 1985).

Heckman, James, "What Has Been Learned about Labor Supply in the Past Twenty Years?" American Economic Review, LXXXIII (1993), 116-121.

Kremer, Michael, "Should Taxes Be Independent of Age?" Harvard University, mimeograph, 1997.

Meyer, Bruce, and Daniel Rosenbaum, "Welfare, the Earned Income Tax Credit, and the Labor Supply of Single Mothers," Quarterly Journal of Economics, CXVI (2001), 1063-1114.

Mirrlees, James A., "An Exploration in the Theory of Optimal Income Taxation," Review of Economic Studies, XXXVIII (1971), 175-208.

, "Migration and Optimal Income Taxes," Journal of Public Economics, XVIII (1982), 319-341.

Murray, Charles, Losing Ground: American Social Policy 1950-1980 (New York: Basic Books, 1984).

Parsons, Donald, "The Health and Earnings of Rejected Disability Insurance Applicants: Comment," American Economic Review, LXXXI (1991), 1419-1426.

Pencavel, John, "Labor Supply of Men," in O. Ashenfelter and R. Layard, eds., Handbook of Labor Economics, Volume I (Amsterdam: North-Holland, 1986).

Piketty, Thomas, "La Redistribution Fiscale face au Chômage," Revue Française d'Economie, XII (1997), 157-201.

Robins, Philip K., "A Comparison of the Labor Supply Findings from the Four Negative Income Tax Experiments," Journal of Human Resources, XX (1985), $567-582$.

Saez, Emmanuel, "Optimal Income Transfer Programs: Intensive versus Extensive Labor Supply Responses," NBER Working Paper No. 7708, 2000.

— - "Using Elasticities to Derive Optimal Income Tax Rates," Review of Economic Studies, LXVIII (2001), 205-229.

Seade, Jesus K., "On the Shape of Optimal Tax Schedules," Journal of Public Economics, VII (1977), 203-236.

, "On the Sign of the Optimum Marginal Income Tax," Review of Economic Studies, XLIX (1982), 637-643.

Tuomala, Matti, Optimal Income Tax and Redistribution (Oxford: Clarendon Press, 1990).

Vickrey, William, Agenda for Progressive Taxation (New York: The Ronald Press Company, 1947). 